\title{
Strategies for lipids and phenolics degradation in the anaerobic treatment of olive mill wastewater
}

\author{
M.R. Gonçalves ${ }^{a, b}$, J.C. Costa ${ }^{a}$, I.P. Marques ${ }^{b}$, M.M. Alves ${ }^{a, *}$ \\ a Institute for Biotechnology and Bioengineering (IBB), University of Minho, 4710-057 Braga, Portugal \\ ${ }^{b}$ Bioenergy Unit, National Laboratory of Energy and Geology, I.P. (LNEG), 1649-038 Lisboa, Portugal
}

\section{A R T I C L E I N F O}

\section{Article history:}

Received 23 July 2011

Received in revised form

18 December 2011

Accepted 19 December 2011

Available online 28 December 2011

\section{Keywords:}

Olive oil mill effluent

Anaerobic digestion

Long-chain fatty acids

Phenolic compounds

Oleic acid

Nitrogen

\begin{abstract}
A B S T R A C T
Strategies are proposed for the anaerobic treatment of lipid and phenolic-rich effluents, specifically the raw olive mill wastewater (OMW). Two reactors were operated under OMW influent concentrations from 5 to $48 \mathrm{~g} \mathrm{COD} \mathrm{L}^{-1}$ and Hydraulic Retention Time between 10 and 5 days. An intermittent feeding was applied whenever the reactors showed a severe decay in the methane yield. This strategy improved the mineralization of oleate and palmitate, which were the main accumulated Long-Chain Fatty Acids (LCFA), and also promoted the removal of resilient phenolic compounds, reaching remarkable removal efficiencies of $60 \%$ and $81 \%$ for two parallel reactors at the end of a feed-less period. A maximum biogas production of $1.4 \mathrm{~m}^{3} \mathrm{~m}^{-3} \mathrm{~d}^{-1}$ at an Organic Loading Rate of $4.8 \mathrm{~kg} \mathrm{COD} \mathrm{m}^{-3} \mathrm{~d}^{-1}$ was obtained. Patterns of individual LCFA oxidation during the OMW anaerobic digestion are presented and discussed for the first time. The supplementation of a nitrogen source boosted immediately the methane yield from 21 and 18 to 76 and $93 \%$ in both reactors. The typical problems of sludge flotation and washout during the anaerobic treatment of this oily wastewater were overcome by biomass retention, according to the Inverted Anaerobic Sludge Blanket (IASB) reactor concepts. This work demonstrates that it is possible to avoid a previous detoxification step by implementing adequate operational strategies to the anaerobic treatment of OMW.
\end{abstract}

(c) 2011 Elsevier Ltd. All rights reserved.

\section{Introduction}

Olive oil has beneficial effects on human health. The lower incidence of coronary heart disease and certain type of cancers in Mediterranean area has been associated to the olive oil intake. These healthy effects are attributed to the high ratio between monounsaturated and saturated fatty acids in olive oil and to the antioxidant property of its phenolic compounds (Tripoli et al., 2005). Fatefully, these compounds are the main responsible for causing inhibition of microbial communities and operational problems during the anaerobic treatment of olive oil mill effluent (Beccari et al., 1999).
Olive mill wastewater (OMW) is a complex effluent obtained from the traditional press and the continuous three-phase mills of olive oil production with a variable amount of lipidic compounds (4-25 g L${ }^{-1}$ ) (Hamdi, 1992; Angelidaki et al., 2002) and phenolic compounds (3-12 $\mathrm{g} \mathrm{L}^{-1}$ ) (Beccari et al., 1999; Khoufi et al., 2006). The anaerobic digestion of raw OMW has been reported as a difficult process (Morillo et al., 2009). Boari et al. (1984) achieved instability and poor reproducibility on the start-up of up-flow anaerobic sludge blanket (UASB) reactors treating OMW. They reported foam formation, accidental organic overloads and biomass washout. Later, Zouari and Ellouz (1996) removed the oil layer from OMW to avoid inhibition caused by lipids.

\footnotetext{
* Corresponding author. Tel.: +351 253604400; fax: +351 253604429.

E-mail address: madalena.alves@deb.uminho.pt (M.M. Alves). 
Nevertheless, it was revealed to be insufficient since the accumulation of recalcitrant coloured compounds caused an irreversible inhibition of bacterial growth. More recently, Khoufi et al. (2006) operated an anaerobic filter packed with polyurethane foam cubes, at an organic loading rate (OLR) of $4 \mathrm{gCOD} \mathrm{L}^{-1} \mathrm{~d}^{-1}$ of raw OMW. They observed a decrease of $\mathrm{pH}$, biogas production and yield and accumulation of VFAs.

Different strategies have been applied to enhance OMW biodegradation. Pre-treatments have been proposed to detoxify the effluent (Azabou et al., 2010; Khoufi et al., 2009). Other researchers decrease OMW toxicity by co-digestion with agro-industrial residues (Dareioti et al., 2010; Fountoulakis et al., 2008). Instead of removing or degrade OMW toxic compounds before the anaerobic treatment, Beccari et al. (1999) and Hamdi (1992) performed batch experiments to get insights to the problem of OMW biodegradation and toxicity. They concluded that among the OMW inhibitory substances, the darkly coloured polyphenols induced the problem of OMW biodegradation, whereas the long-chain fatty acids (LCFA), tannins, and simple phenolic compounds were responsible for its toxicity to methanogenic bacteria.

Olive oil is composed of triglycerides that consist of a mixture of LCFA, mainly oleic acid bonded to glycerol. Microbial oxidation of LCFA has been intensively studied (Lalman and Bagley, 2001; Pereira et al., 2002, 2004). The two main problems related to the treatment of lipids/LCFA containing effluents are sludge flotation and biomass washout due to the adsorption of lipids/LCFA onto the biomass and inhibition of anaerobic microbial communities by LCFA (Hwu et al., 1998; Kim et al., 2004). The operational problems caused by LCFA led researchers to find new strategies to treat oily wastewaters (Pereira et al., 2005; Kuang et al., 2006; Cavaleiro et al., 2009; Palatsi et al., 2009). The new concepts to enhance lipids degradation based on reactors operation and feeding strategies are promising to real oily effluents depuration (Alves et al., 2009). However, most of these studies were accomplished with LCFA/lipid-based synthetic effluents, avoiding the interfering presence of other compounds usually present in real effluents. Moreover, less attention has been given to the patterns of individual LCFA oxidation during the operation of reactors treating real/industrial complex oily wastes and wastewaters (Jeganathan et al., 2006; MartínGonzález et al., 2011; Neves et al., 2009a). Until now, the behaviour of individual LCFA during the continuous anaerobic digestion of OMW has not been reported.

In this work, different strategies to convert efficiently OMW to methane and to prevent and recover inhibited reactors by lipids/LCFA were investigated concerning, mainly, the inoculum type, the feeding mode, nutrients requirement and the reactor design. The degradation of individual LCFA was monitored along the reactors operation to assess the accumulated intermediates. The removal of phenolic compounds was examined.

\section{Methods}

\subsection{Inoculum and substrate}

Two different inocula - sludge acclimated to oleate (S1) and non-acclimated sludge (S2) - were used for the reactors operation. The sludge acclimated to oleate was obtained as described elsewhere (Cavaleiro et al., 2009) with a specific methanogenic activity (SMA) of $0.43 \pm 0.05$ and $1.43 \pm 0.03 \mathrm{~g} \mathrm{COD}^{-\mathrm{CH}_{4}(\mathrm{STP})} \mathrm{gVS}^{-1} \mathrm{~d}^{-1}$ for acetate and $\mathrm{H}_{2} / \mathrm{CO}_{2}$, respectively. The non-acclimated sludge was obtained from a domestic wastewater treatment plant with a SMA of $<0.05$

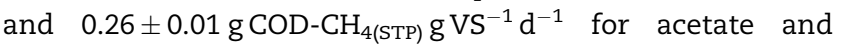
$\mathrm{H}_{2} / \mathrm{CO}_{2}$, correspondingly. OMW was obtained from a threephase continuous olive oil extraction process (Amarante, Portugal). The substrate was stored at $-20^{\circ} \mathrm{C}$ until being used. The effluent was characterised and the mean values obtained are summarized in Table 1.

\subsection{Analytical methods}

Total and soluble chemical oxygen demand $\left(\mathrm{COD}_{t}\right.$ and $\left.\mathrm{COD}_{\mathrm{s}}\right)$ and total nitrogen $\left(\mathrm{N}_{\mathrm{t}}\right)$ were determined using test kits (Hach Lange, Germany). Total, volatile and volatile suspended solids (TS, VS and VSS) were determined according to Standard Methods (APHA et al., 1998). Total phenols (TPh) were evaluated by a modified Folin-Ciocalteau method (Singleton and Rossi, 1965). Colour was determined by measuring the absorbance at $390 \mathrm{~nm}$. LCFA (myristic (C14:0), palmitic (C16:0), palmitoleic (C16:1), stearic (C18:0), oleic (C18:1) and linoleic (C18:2)) in the solid and liquid phases of the reactors content were analysed according to Neves et al. (2009a). Methane produced in batch experiments was analysed in a gas chromatograph (Chrompack 9000) equipped with a FID detector and a $2 \mathrm{~m} \times 1 / 8^{\prime \prime}$ Chromosorb 101 (80-120 mesh) column. Nitrogen was used as carrier gas $\left(30 \mathrm{~mL} \mathrm{~min}^{-1}\right)$. The column, injector, and detector temperatures were 35,110 , and $220^{\circ} \mathrm{C}$, respectively. Methane produced in the reactors was analysed in a Micro Gas Chromatograph (CP-4900, Varian), equipped with a TCD column. Helium was used as carrier gas (150 kPa) and the temperatures of the column and injector were 80 and $110^{\circ} \mathrm{C}$, respectively. Specific methanogenic activities (SMA) of both inocula (S1 and S2) were measured as described elsewhere (Gonçalves et al., 2011) using acetate (30 mM) and

Table 1 - Olive mill wastewater characterisation.

\begin{tabular}{|c|c|}
\hline Parameter & Average \pm Error $^{\mathrm{a}}$ \\
\hline $\mathrm{pH}$ & $4.7 \pm 0.1$ \\
\hline Total COD $\left(\mathrm{g} \mathrm{L}^{-1}\right)$ & $130.1 \pm 7.4$ \\
\hline Soluble COD $\left(\mathrm{g} \mathrm{L}^{-1}\right)$ & $69.4 \pm 1.4$ \\
\hline Total solids ( $\left.\mathrm{g} \mathrm{L}^{-1}\right)$ & $75.5 \pm 3.1$ \\
\hline Volatile solids $\left(\mathrm{g} \mathrm{L}^{-1}\right)$ & $54.4 \pm 3.4$ \\
\hline Volatile suspended solids $\left(\mathrm{gL}^{-1}\right)$ & $34.6 \pm 3.3$ \\
\hline Total nitrogen $\left(\mathrm{mg} \mathrm{L}^{-1}\right)$ & $460.0 \pm 53.2$ \\
\hline Total phenols (gallic acid, $\mathrm{gL}^{-1}$ ) & $4.3 \pm 0.4$ \\
\hline Colour (Abs@390 nm) & $22.5 \pm 1.7$ \\
\hline Oil and grease $\left(\mathrm{g} \mathrm{L}^{-1}\right)$ & $13.6 \pm 1.5$ \\
\hline Total free-LCFA ( g COD L $^{-1}$ ) & $6.2 \pm 3.8$ \\
\hline$\%$ C18:1 & $78.1 \pm 10.9$ \\
\hline$\%$ C16:0 & $10.2 \pm 5.5$ \\
\hline \% C18:2 & $7.6 \pm 4.9$ \\
\hline$\%$ C18:0 & $4.1 \pm 1.5$ \\
\hline
\end{tabular}

a Data are expressed as an average \pm error ( $95 \%$ confidence) of six replicates; LCFA - long-chain fatty acids. 
$\mathrm{H}_{2} / \mathrm{CO}_{2}(80 / 20 \mathrm{v} / \mathrm{v}, 1$ bar) as substrates. Methane production was corrected for standard temperature and pressure (STP) conditions.

\subsection{Reactors: experimental set-up and operation mode}

Two up-flow anaerobic reactors of $2.5 \mathrm{dm}^{3}$ (useful volume) were used. They consisted in an anaerobic chamber and an external jacket which kept the temperature at $37^{\circ} \mathrm{C}$. A solid-gas liquid separator was connected at the middle of the reactor to avoid washout and to promote the degradation of the accumulated substrate onto the biomass (Fig. 1).

Reactors R1 and R2 were inoculated with S1 and S2, respectively. The initial biomass concentration in both reactors was approximately $10 \mathrm{~g} \mathrm{VS} \mathrm{L}^{-1}$. OMW was diluted with tap water. Sodium bicarbonate $\left(5 \mathrm{gL}^{-1}\right)$ was added to provide neutral $\mathrm{pH}$ and suficient alkalinity inside the reactor. The reactors operation was performed in two phases and the conditions are presented in Table 2. The first phase, from period I to III, was characterised by the intermittent feeding of the reactors and the nitrogen non-addition (COD: $N$ of 230-270:1). Two batch periods were applied (B1 and B2) in reactor $\mathrm{R} 1$ and one batch period (B1) in reactor $\mathrm{R} 2$. In the second phase (from period IV to VII), both reactors were operated in a continuous mode and an additional nitrogen source $\left(\mathrm{NH}_{4} \mathrm{Cl}\right)$ was used to provide an influent with a COD:N ratio of 100:1. In this phase the organic loading rates (OLR) were increased by varying the COD influent from 10 to $48 \mathrm{~g} \mathrm{COD} \mathrm{L}^{-1}$ and the hydraulic retention time (HRT) from 10 to 6 days. Biogas was measured daily by a gas meter (Milligascounter, Ritter, Germany) and corrected for standard temperature and pressure (STP) conditions. The effluents were analysed twice a week in terms of total and soluble COD, $\mathrm{TPh}$, colour and solids. LCFA were measured the beginning and end of the periods.

The produced methane was converted to its equivalent $\mathrm{COD}\left(\mathrm{kgCOD}-\mathrm{CH}_{4}\right)$ considering the theoretical methane potential $\left(0.35 \mathrm{~m}^{3} \mathrm{CH}_{4} \mathrm{~kg}^{-1} \mathrm{COD}\right)$. The methane yields were calculated using the following equation (Eq. (1)):

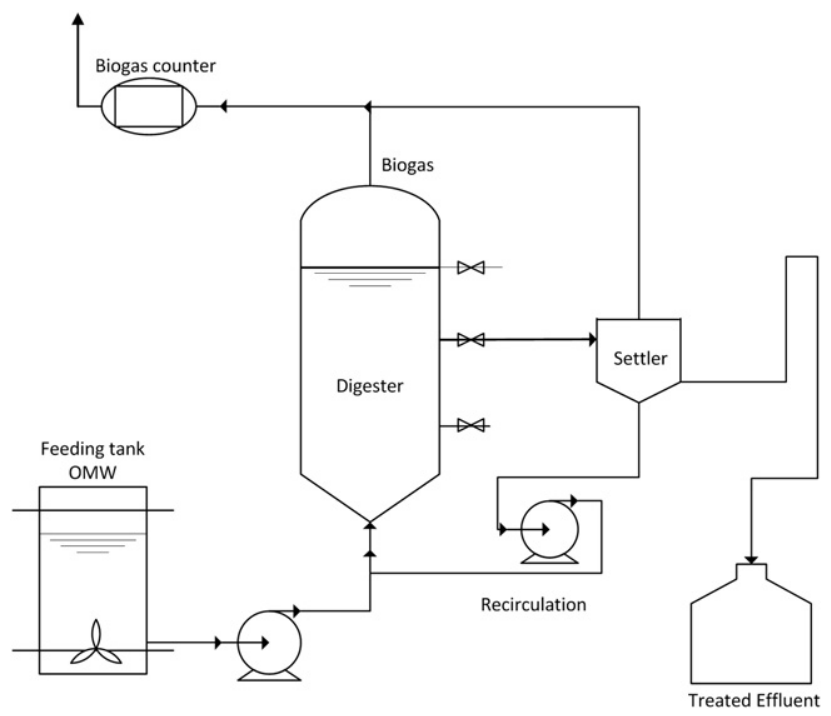

Fig. 1 - Reactors experimental set.
Methane Yield $(\%)=\frac{\mathrm{CH}_{4} \text { produced }(\mathrm{kg} \mathrm{COD} / \mathrm{d})}{\mathrm{COD} \text { removed }(\mathrm{kg} \operatorname{COD} / \mathrm{d})} \times 100$

\section{Results}

\subsection{First experimental phase: effect of intermittent feeding on $\mathrm{CH}_{4}$ production and COD conversion}

The reactors start-up was performed with diluted OMW (4.8 $\mathrm{g} \mathrm{COD} \mathrm{L}^{-1}$ ) at an HRT of 10 days along 50 days (Fig. 2 Period I). In this period, both reactors showed an average biogas production of $0.13 \mathrm{~m}^{3} \mathrm{~m}^{-3} \mathrm{~d}^{-1}$, COD removal up to $88 \%$ and methane percentages in biogas higher than $60 \%$. R1 was more stable than R2 in Period I. However, when the OLR was increased twofold by changing the HRT from 10 to 5 days, a sudden decrease of biogas production occurred in R1 (Period II-a), which, after 15 days, achieved values as low as $30 \%$ and $5 \%$, for the percentage of methane in the biogas and for the methane yield, respectively. In order to avoid a complete inhibition, the reactor feeding was stopped and a batch period was initiated (Period B1). Biogas production was noticed during the batch period. Once the biogas production stopped, the feeding was restarted at the same conditions of Period II-a. Notwithstanding the recovery of biogas quality $\left(\mathrm{CH}_{4}\right.$ content around $50 \%$ ) and of methane production, the overall methane yield remained low, between 20 and $30 \%$ of the theoretical value. Therefore, a new batch period was applied (B2).

In reactor R2, only one batch period was applied on day 130, when the reactor was almost failing. The biogas production increased when the feed was stopped, as observed in reactor R1. To ascertain if the HRT contributed for reactors disturbance, in period III, 10 days of HRT was reapplied to both reactors. OMW concentration was increased to $10 \mathrm{~g} \mathrm{COD} \mathrm{L}^{-1}$ to maintain the OLR of the previous period. In this period, both reactors showed a slight recovery of the system performance since $\mathrm{CH}_{4}$ percentage and COD removal efficiency increased until values of $60 \%$ and $80 \%$, correspondingly. Nevertheless, the overall methane yields of the reactors remained low, achieving values of only 21 and $18 \%$ for R1 and R2, respectively. One of the main limitations that were behind the low methane yields obtained could be the low nitrogen content of the OMW. Therefore this aspect was studied in a second experimental phase.

\subsection{Second experimental phase: nitrogen supplementation effect and continuous feeding}

The required COD:N:P ratio depends on the loading rate and a reasonable ratio for highly loaded processes $\left(0.8-1.2 \mathrm{kgCOD} \mathrm{kg} \mathrm{VSS}^{-1} \mathrm{~d}^{-1}\right)$ is 250:5:1 (Droste, 1997). Recently it has been suggested that nutrients in wastewater treatment processes are often more than the required, since the COD removal efficiencies and the biomass yield are usually not considered (Ammary, 2005; Hussain et al., 2008). The comparison of the reactors performance with other works in terms of COD: $N$ ratios, COD removal and methane efficiencies is presented in Table 3. Ammary (2005) reported that the OMW with a COD:N:P ratio of 911:5:1.7 had the sufficient nutrients to have an efficient treatment. The author obtained 
Table 2 - Operational conditions applied to reactors R1 and R2.

Phase feeding mode

Period
R1

$\begin{array}{ccc}\text { Days } & \begin{array}{c}\text { HRT } \\ \text { (d) }\end{array} & \begin{array}{l}\text { OLR applied } \\ \left(\mathrm{kg} \mathrm{m}^{-3} \mathrm{~d}^{-1}\right)\end{array}\end{array}$

R2

Period Days HRT

HRT
(d)

OLR applied $\left(\mathrm{kg} \mathrm{m}^{-3} \mathrm{~d}^{-1}\right)$

\begin{tabular}{lllllllll}
\hline 1st phase & I & $0-50$ & 10 & $0.5 \pm 0.0$ & I & $0-50$ & 10 & $0.5 \pm 0.0$ \\
intermittent feeding & II-a & $51-66$ & 5 & $1.0 \pm 0.2$ & II & $51-129$ & 5 & $0.9 \pm 0.1$ \\
& B1-Batch & $67-92$ & - & 0 & & & \\
& II-b & $93-129$ & 5 & $0.9 \pm 0.1$ & & & \\
& B2-Batch & $130-168$ & - & 0 & B1-Batch & $130-175$ & - & 0 \\
& III & $169-211$ & 10 & $1.0 \pm 0.1$ & III & $176-211$ & 10 & $1.0 \pm 0.1$ \\
2nd phase & IV & $212-254$ & & $1.0 \pm 0.0$ & IV & $212-254$ & $1.0 \pm 0.0$ \\
continuous feeding & V & $255-287$ & & $1.9 \pm 0.2$ & V & $255-287$ & $1.9 \pm 0.2$ \\
& VI & $288-318$ & & $3.1 \pm 0.2$ & VI & $288-318$ & $3.1 \pm 0.2$ \\
& VII & $319-347$ & & $4.8 \pm 0.5$ & VII & $319-347$ & 6 & $4.5 \pm 0.3$ \\
\hline
\end{tabular}

R1 - Reactor 1; R2 - Reactor 2; OLR - organic loading rate; HRT - hydraulic retention time. high COD removals of about $83 \%$, but the methane yield was not discussed. Hussain et al. (2008) concluded that the optimum COD:N:P estimated for phenolic wastewater treatment is 300:1:0.1. They refer that the variation of COD:N:P from 30:1:0.1 to 300:1:0.1 did not influence the conversion of phenol COD to methane COD. The option of studying, in a first phase, the degradation of OMW without nitrogen addition was based in those studies. From Period I to III, the OMW COD/N ratio ranged from 230:1 to 270:1. The OMW degradation without nitrogen addition led to COD removals of $70-72 \%$ but the COD mineralization to methane was low, mainly in the periods II and III. In period IV, a nitrogen source was supplemented to both reactors increasing the COD:N ratio to 100:1 and it corresponded to a concentration of about $100 \mathrm{mg} \mathrm{N} \mathrm{L}^{-1}$. The overall methane yield increased immediately from 21 and $18 \%$ to 76 and $93 \%$, for reactors R1 and R2, respectively (Table 3). After 9 days of operation with the supplemented feed, it was obtained an effluent with 30 and $37 \mathrm{mg} \mathrm{N} \mathrm{L}^{-1}$ for reactors
R1 and R2, respectively. At the end of period IV (after 43 days), the effluents from reactors R1 and R2 presented an effluent with 78 and $52 \mathrm{mg} \mathrm{N} \mathrm{L}^{-1}$, respectively. Nitrogen addition was, in this case, essential to convert efficiently OMW to methane.

From period IV to VII, the reactors were operated in continuous mode along 135 days at an OLR between 1.0 and $4.8 \mathrm{~kg} \mathrm{COD} \mathrm{m}^{-3} \mathrm{~d}^{-1}$, corresponding to an influent COD increment from 10 to $48 \mathrm{gCOD} \mathrm{L}^{-1}$. Table 4 presents the reactors performance in terms of biogas production, methane content and COD conversion. For reactor R1, a gradual enhancement of biogas productivities was observed till $1.4 \mathrm{~m}^{3} \mathrm{~m}^{-3} \mathrm{~d}^{-1}$, at an OLR of $4.8 \mathrm{kgCOD} \mathrm{m}^{-3} \mathrm{~d}^{-1}$. COD removal efficiencies of $81-87 \%$ were achieved and the average of the methane content in biogas varied between 70 and $74 \%$. A different approach was applied for R2 in the last period. The OLR was increased by changing the HRT from 10 to 6 . The objective was to optimise the reactors operation and to verify if the HRT change, at this stage, would cause any severe disturbance, as
R1

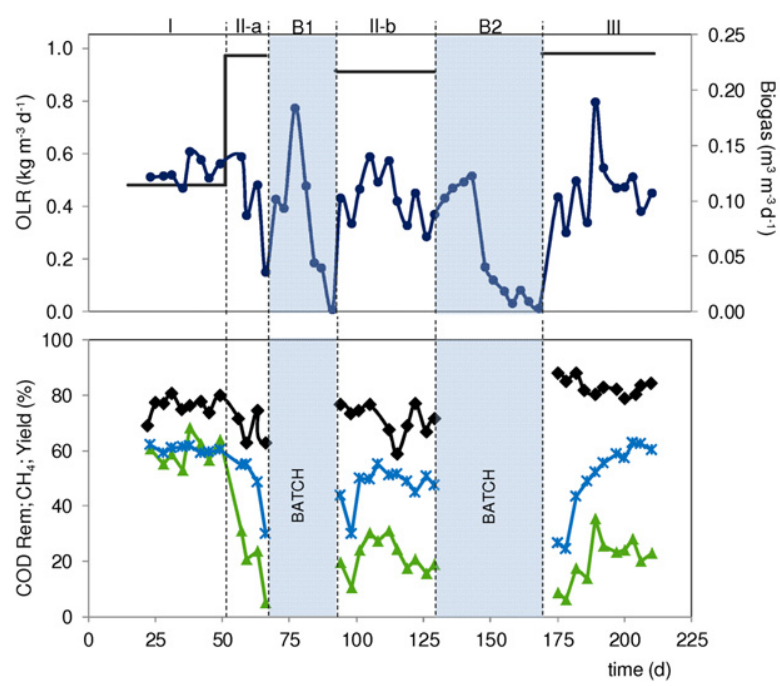

R2

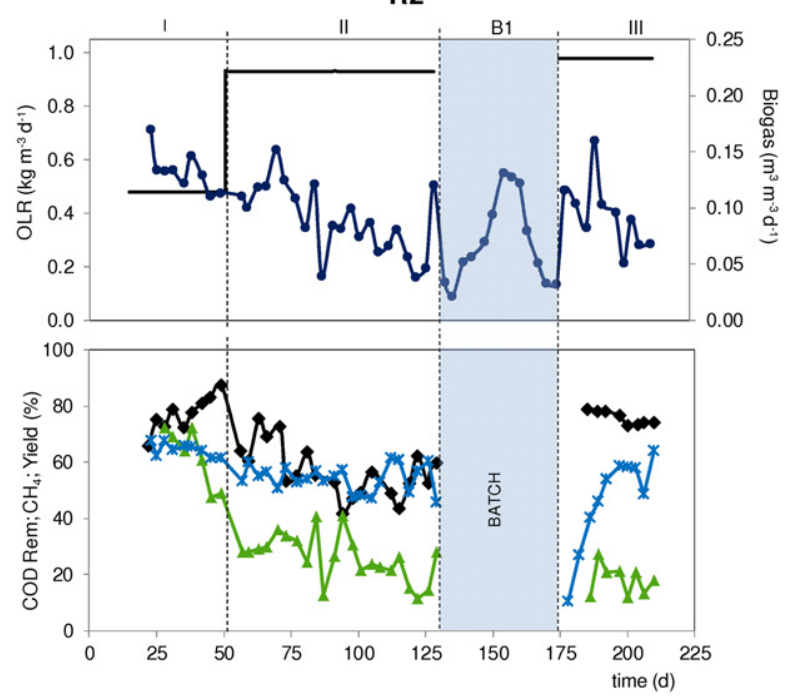

Fig. 2 - Performance data during the 1st phase of operation (intermittent feeding mode). Biogas production ( $\bullet$ ), percentage of methane in the biogas $(*)$, total COD removal efficiencies $(\bullet)$ and $\mathrm{CH}_{4}$ yield $(\Delta)$ are presented for reactors $\mathrm{R} 1$ and $\mathrm{R} 2$. 
Table 3 - Effect of nitrogen addition. Comparison of reactors performance data with results in literature.

\begin{tabular}{llcccc} 
COD:N & Substrate & OLR $\left(\mathrm{kg} \mathrm{m}^{3} \mathrm{~d}^{-1}\right)$ & CODr $(\%)$ & Y CH & Reference \\
\hline 182:1 & OMW & 5.3 & 83 & n.d. & Ammary (2005) \\
300:1 & Phenolic & $3.9-4.1$ & $95-99$ & 90 & Hussain et al. (2008) \\
& wastewater & & & & This work \\
$230: 1$ & OMW & 0.5 & $72^{\mathrm{a}} ; 70^{\mathrm{b}}$ & $60^{\mathrm{a}} ; 62^{\mathrm{b}}$ & Period I \\
$270: 1$ & OMW & 1.0 & $82^{\mathrm{a}} ; 76^{\mathrm{b}}$ & $21^{\mathrm{a}} ; 8^{\mathrm{b}}$ & Period III \\
$100: 1$ & OMW & 1.0 & $84^{\mathrm{a}} ; 85^{\mathrm{b}}$ & $76^{\mathrm{a}} ; 93^{\mathrm{b}}$ & Period IV \\
\hline
\end{tabular}

n.d. - non-determined, CODr - COD removal; OLR - organic loading rate; $\mathrm{Y} \mathrm{CH}_{4}$ - methane yield; OMW - olive mill wastewater.

a Reactor R1.

b Reactor R2

occurred in a previous period. For comparison, it was applied a similar OLR on R1, by increasing the influent COD and keeping the HRT in 10 days. At this period, the decrease of HRT did not promote a severe inhibition of the reactor, suggesting that biomass was gradually acclimated to OMW.

The addition of alkali was kept constant during all operation. However, it is important to note that at higher concentrations of OMW (27-48 $\mathrm{g} \mathrm{COD} \mathrm{L}^{-1}$ ), the $\mathrm{pH}$ in the feeding tank decreased from values of 7-8 to values around 5.3-6.5. Although the low $\mathrm{pH}$ in the feeding tank, a neutral $\mathrm{pH}$ was kept inside the reactor during all operation.

\subsection{Long-chain fatty acids oxidation: intermittent and continuous feeding}

In R1, LCFA accumulated during the periods II-a and II-b, achieving maximum values of 0.18 and $0.11 \mathrm{gCOD}$ LCFA g VS ${ }^{-1}$, respectively (Fig. 3). These LCFA concentrations were obtained at the time that an inhibitory effect occurred, causing almost cessation of biogas production. A higher

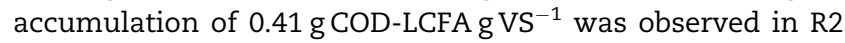
since the single batch period was only applied at day 130 . The LCFA content inside the reactors was significantly lower at the end of the batch periods. The ratio between the LCFA degraded and the methane produced during the batch periods was 0.91 and 0.60 for B1 and B2 of reactor R1, respectively, and 0.58 for reactor $\mathrm{R} 2$.

In the second experimental phase, no feed-less periods were applied. At this phase, LCFA started to accumulate again, when the OLR was increased to $1.9,3.1$ and 4.5 or $4.8 \mathrm{kgCOD} \mathrm{m}^{-3} \mathrm{~d}^{-1}$ (Periods V-VII). At the end of operation (Period VII), the reactors showed similar concentrations of

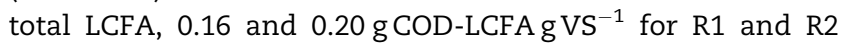
respectively, as well as similar individual LCFA concentrations. Interestingly, in the first periods of reactors operation, oleate (C18:1) was the main LCFA compound accumulated in proportions of $40-51 \%$ and $48-51 \%$ for $\mathrm{R} 1$ and $\mathrm{R} 2$ respectively, followed by palmitate (C16:0) and stearate (C18:0). Afterwards, a shift in the LCFA accumulation pattern was noticed. In the final periods of the reactors operation, palmitate started to accumulate inside the reactors at higher concentrations than oleate (Periods VI and VII). At period VII, palmitate represented 69 and 56\% of total LCFA for R1 and R2, respectively. Stearate increased slightly in both reactors but was always low and palmitoleate (C16:1) was not detected during all the experimental operation. Linoleate was always present at low concentrations.

\subsection{Phenolic compounds}

An improvement of phenols removal was observed in both reactors, mainly during period I, demonstrating an adaptation of the microbial consortium to phenolic compounds. Afterwards, the average values of phenolic removal efficiencies during feeding periods were about 43 and 38\%, ranging from 30 to 57 and from 24 to $57 \%$, for reactors R1 and R2, respectively (Fig. 4). During the batch periods, the effluent phenolic concentration decreased, and removal efficiencies of $60 \%$ (R1)

Table 4 - Reactors performance data of the 2nd experimental phase (continuous feeding mode; COD:N = 100:1).

\begin{tabular}{|c|c|c|c|c|c|c|}
\hline Reactor & Period & Inf. CODt $\left(\mathrm{kg} \mathrm{m}^{-3}\right)$ & $\operatorname{Biogas}\left(\mathrm{m}^{3} \mathrm{~m}^{-3} \mathrm{~d}^{-1}\right)$ & $\mathrm{CH}_{4}(\%)$ & Rem CODt (\%) & $\mathrm{CH}_{4}$ Yield (\%) \\
\hline \multirow[t]{4}{*}{ R1 } & IV & $9.9 \pm 0.8(13)$ & $0.29 \pm 0.05$ & $76.9 \pm 3.8$ & $83.7 \pm 2.3(10)$ & $76.4 \pm 10.5$ \\
\hline & $\mathrm{V}$ & $19.3 \pm 2.5$ & $0.51 \pm 0.04$ & $72.6 \pm 6.1$ & $86.6 \pm 1.5$ & $63.6 \pm 6.1$ \\
\hline & VI & $30.6 \pm 2.3$ & $0.83 \pm 0.03$ & $72.0 \pm 8.2$ & $87.0 \pm 1.1$ & $65.2 \pm 8.6$ \\
\hline & VII & $47.5 \pm 4.7$ & $1.40 \pm 0.24$ & $70.4 \pm 2.1_{(6)}$ & $80.8 \pm 4.1$ & $73.2 \pm 11.7$ \\
\hline \multirow[t]{4}{*}{ R2 } & IV & $9.9 \pm 0.8{ }_{(13)}$ & $0.34 \pm 0.06$ & $79.8 \pm 3.2$ & $84.5 \pm 3.7$ & $92.5 \pm 15.1$ \\
\hline & V & $19.3 \pm 2.5$ & $0.47 \pm 0.02$ & $74.3 \pm 4.0$ & $88.5 \pm 1.5(6)$ & $58.8 \pm 2.4$ \\
\hline & VI & $30.6 \pm 2.3$ & $0.75 \pm 0.02$ & $72.4 \pm 5.8$ & $86.0 \pm 2.0$ & $59.4 \pm 5.7$ \\
\hline & VII & $27.0 \pm 2.0$ & $1.07 \pm 0.19$ & $70.8 \pm 5.0$ & $76.3 \pm 4.4$ & $61.5 \pm 9.7$ \\
\hline
\end{tabular}

Data are expressed as an average \pm standard deviation. The number of data is presented in brackets. Inf CODt - influent total COD; Rem CODt total COD removal. 

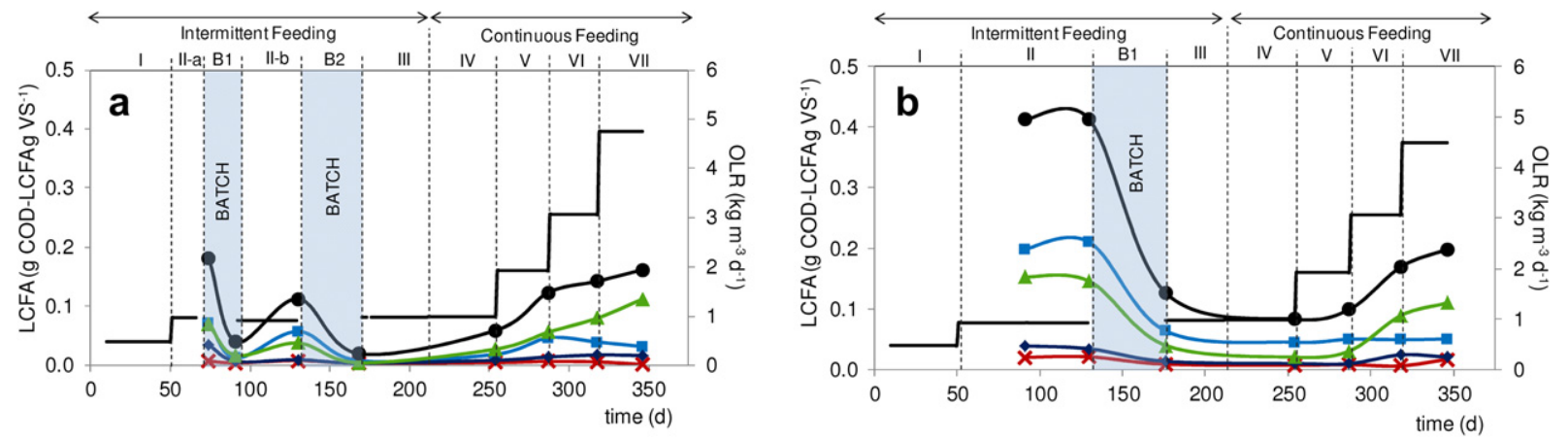

Fig. 3 - Long-chain fatty acids monitoring during overall experimental periods for reactors R1 (a) and R2 (b). Total LCFA (•), oleate $(\square)$, palmitate $(\Delta)$, stearate $(\diamond)$, linoleate $(\times)$.

and $81 \%$ (R2) were obtained, representing respectively a remarkable additional conversion of 20 and $50 \%$ of phenolics. In the second experimental phase, the influent phenolic concentration increased from 0.2 to $1.8 \mathrm{~g} \mathrm{~L}^{-1}$, but the removal of phenolics was not affected. A brown effluent colouration was obtained during all operation mainly caused by the remaining fraction of recalcitrant phenolic compounds. This fact indicates that the digested effluent needs a posttreatment to accomplish the discharge limits of sewer systems.

\section{Discussion}

The recent trends in the research of OMW treatment and valorization comprise the degradation of the inhibitory compounds before the anaerobic digestion process (Azabou et al., 2010; Khoufi et al., 2009). Nevertheless, lipids are attractive for biogas production because they have a high methane yield potential (Alves et al., 2009). Several strategies to optimise the degradation of lipids/LCFA and to recover inhibited reactors by LCFA had been recently discovered (Cavaleiro et al., 2009; Palatsi et al., 2009, 2010; Zhang et al., 2011). In this work, we propose different strategies to convert efficiently OMW to methane and to overcome the problems caused by lipids/LCFA.

The first tested strategy consisted of using an acclimated inoculum to oleate for the start-up of one of the reactors (R1).
The other reactor (R2) was inoculated with non-acclimated sludge, for comparison. It has been reported that the tolerance to LCFA toxicity can be improved by promoting biomass adaptation (Cavaleiro et al., 2009; Palatsi et al., 2010). In fact, the use of an adapted inoculum to oleate enhanced the conversion of OMW to methane in batch experiments (Gonçalves et al., 2011). However, in this work, the use of an acclimated inoculum to oleate only provided a more stable process at the start-up (Fig. 2 - Period I), not being its use required, mainly for a long term operation. Indeed, the HRT change, in the subsequent period, promoted a decay of the methane production and the accumulation of LCFA in both reactors.

The second tested strategy (intermittent feeding) was used to promote the oxidation of lipids/LCFA present in OMW and, consequently, to recover inhibited reactors and enhance the methane production. This procedure was demonstrated before by Cavaleiro et al. (2009) as a good strategy to promote the degradation of LCFA in a reactor fed with an oleate-based synthetic wastewater. However, being OMW a matrix of complex compounds including phenolics besides oils and LCFA, the previous results cannot be extrapolated without experimental validation. In the present work, a feed-less period was applied whenever the reactors showed a severe decay in the methane yield. The decrease of the methane production was accompanied by a stable COD removal (Fig. 2 - Period IIa). Jeganathan et al. (2006) operated three different UASB reactors with
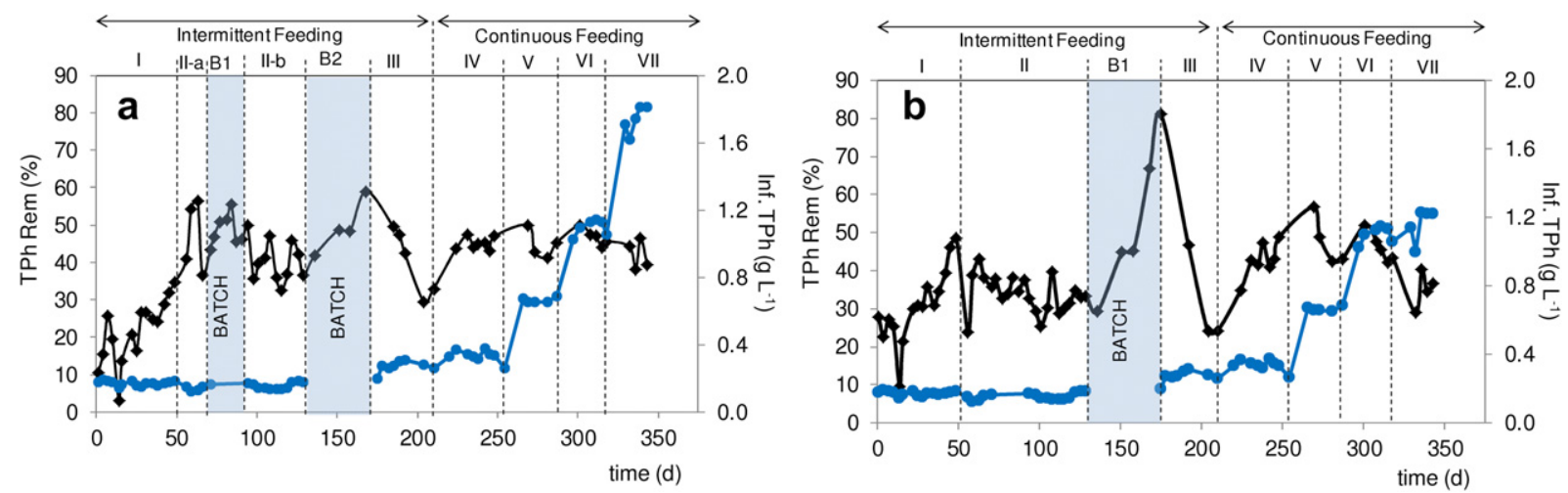

Fig. 4 - Phenolic compounds removal $(\diamond)$ and influent total phenols concentration $(\bullet)$ during overall experimental periods for reactors R1 (a) and R2 (b). 
a complex oily wastewater and, similarly to this work, they observed a drop in biogas production despite the fact that COD removal efficiencies remained several days above $80 \%$. The accumulated substrate inside the reactor was mainly due to LCFA adsorption onto the biomass. The batch periods promoted the degradation of LCFA, showing that the inhibition was reversible.

In a previous work, Pereira et al. (2004) found that biomass encapsulated with an amount of $1 \mathrm{gCOD}$-LCFA g VS $^{-1}$ was able to convert this biomass-associated LCFA (mainly palmitic acid) into methane at a maximum rate of $500 \mathrm{mgCOD}$ $\mathrm{CH}_{4} \mathrm{~g} \mathrm{VSS}^{-1} \mathrm{~d}^{-1}$. The maximum values of biomass-associated LCFA obtained for R1 and R2 (0.18 and $0.41 \mathrm{~g} \mathrm{COD-LCFA} \mathrm{g} \mathrm{VS}^{-1}$ ) are lower than the value proposed by Pereira et al. (2004) and were mainly due to oleate, followed by palmitic and stearate. However, due to the complex nature of OMW, involving a matrix of organics, including phenolic compounds, it is not surprising that a different pattern of LCFA behaviour was obtained in the present work, comparing to the previous experiments where a simple oleate-based substrate was used to study the accumulation and degradation of LCFA. Neves et al. (2009b) also found a lower threshold value for LCFA accumulation onto the solid matrix of about $0.18-0.22 \mathrm{~g}$ CODLCFA g TS ${ }^{-1}$ in the co-digestion of cow manure, food waste and oily waste. In the present work, the main accumulated LCFA shifted according to the reactor conditions, similarly in both reactors. Oleate was initially the main accumulated LCFA. Then, palmitate started to accumulate at higher concentrations than oleate, stearate was slightly increasing and palmitoleate was not detected (Periods VI and VII). The oleate conversion to stearate and then palmitate by a step of $\beta$-oxidation is more likely to occur than the direct $\beta$-oxidation of oleate to palmitoleate (Sousa, 2006). The LCFA degradation mechanism is still unclear (Sousa, 2006). Palmitic acid has been indicated as the primary detected product from oleic degradation (Lalman and Bagley, 2001; Pereira et al., 2002). Oleate accumulation was observed as well by Cirne et al. (2007) in the treatment of a lipid-rich (triolein) model waste in batch tests. The experimental results suggest that the metabolic pathways or the limiting step may change during the treatment of OMW, stimulated by the increase of higher lipids/LCFA concentrations.

Surprisingly, the intermittent feeding also improved the removal of resilient phenolic compounds reaching the remarkable removal efficiencies of $60 \%$ and $81 \%$ for the two reactors at the end of a feed-less period. The phenolic compounds that remained inside the reactor could have been degraded, adsorbed or precipitated with proteins, according to the literature. Field and Lettinga (1987) reported that tannin polymers can be effectively adsorbed or precipitated with proteins which lead to its toxic effect. Zouari and Ellouz (1996) mentioned that the accumulation of recalcitrant coloured compounds in the sludge induced an irreversible inhibition of bacterial growth. In our work, a permanent or an irreversible inhibition was not verified since, the increase of phenols concentration from 0.2 to $1.8 \mathrm{~g} \mathrm{~L}^{-1}$ did not cause a negative effect on the removal ability of the reactors. Nevertheless, the explanation (degradation or a physical mechanism) for the removal of more than $50 \%$ of phenolics during the batch periods is still unclear.
LCFA was not the only inhibitory cause throughout the experiment. It was found that nitrogen deficiency in the influent was also the reason for the low methane yields. The supplementation of a nitrogen source boosted immediately the methane yield from 21 and 18 to 76 and 93\%, in the two reactors, and maintained LCFA concentration at low levels. Based on the experimental results, it was supposed that the effect of LCFA inhibition was decreased by the addition of nitrogen, which promoted the growth of new bacterial cells and, consequently, an increase of the ratio biomass-lipids/ LCFA. This hypothesis is supported by the findings of other authors. For instance, Palatsi et al. (2009) found that the increase of the biomass/LCFA ratio by dilution with active inoculum was a good recovery strategy for LCFA inhibited reactors. Additionally, Kuang et al. (2006) reported that the addition of cysteine (nitrogen source) stimulated the increase of the number of bacteria cells, enhancing the degradation of lipids.

The OLR increase, during the continuous operation, promoted the accumulation of LCFA in both reactors. The LCFA levels were considered as inhibitory concentrations in previous periods. Nevertheless, at this stage, the reactors were not inhibited. Probably, an acclimated consortium capable of adsorbing/degrading higher amounts of LCFA was developed. The results showed an improvement of reactors performance suggesting that biomass was gradually acclimated to olive mill effluent and to its toxic/recalcitrant compounds. The experimental data suggest that the biomass adaptation process to the effluent was more effective than the use of an inoculum previously acclimated to successive exposure to an LCFA inhibitory compound.

The reactor configuration (Fig. 1) was vital to overcome the operational problems caused by lipids. The reactor was designed according with the novel patented IASB reactor concepts, namely the encapsulated biomass retention through flotation and LCFA biomass-free retention through settling (Alves et al., 2007). This configuration allowed the well-functioning of the reactor treating a complex oily wastewater. The obtained methane production from OMW with a concentration of almost $50 \mathrm{~g} \mathrm{COD} \mathrm{L}^{-1}$ suggests that the pre-treatments used to decrease OMW toxicity (Khoufi et al., 2006, 2009; Azabou et al., 2010) could be avoided in order to maximize the energy recovery from the effluent.

\section{Conclusions}

Strategies for an effective anaerobic treatment and valorization of OMW were proposed in this work. The main conclusions were:

1. Alternating periods of continuous OMW feed and batch operations enhanced the mineralization of LCFA inside the reactor and prevent its excessive accumulation. The intermittent feeding also improved the removal of resilient phenolic compounds.

2. Oleate and palmitic were the main LCFA intermediates from olive oil mill effluent degradation that accumulated inside the reactor. The profile of adsorbed LCFA shifted according to the operational conditions. 
3. The use of an acclimated sludge was only relevant in the reactor start-up.

4. Nitrogen supplementation was essential for an efficient digestion of OMW, since its addition promptly boosted the reactors methane yield from 21 and 18 to 76 and 93\% respectively in both reactors.

5. Biomass retention accordingly to the Inverted Anaerobic Sludge Blanket (IASB) reactor concepts was essential to overcome the typical LCFA degradation problems of sludge flotation and washout.

\section{Acknowledgements}

The authors acknowledge the financial support of the "Fundação para a Ciência e a Tecnologia", FCT/MCTES, through the project PTDC/ENR/69755/2006 and also through the grants given to Marta Gonçalves SFRH/BD/40746/2007 and José Carlos Costa SFRH/BDP/48962/2008. The authors thank Tânia Ferreira for the help in LCFA analysis and Ana Cavaleiro for her scientific support.

\section{R E F E R E N C E S}

Alves, M.M., Pereira, M.A., Sousa, D.S., Cavaleiro, A.J., Picavet, M., Smidt, H., Stams, A.J.M., 2009. Waste lipids to energy: how to optimize methane production from long-chain fatty acids (LCFA). Microbial Biotechnology 2 (5), 538-550.

Alves, M.M., Picavet, M.A., Pereira, M.A., Sousa, D.Z., Cavaleiro, A.J., 2007. Novel anaerobic reactor for the removal of long chain fatty acids from fat containing wastewater. WO/2007/ 058557.

Ammary, B.Y., 2005. Treatment of olive mill wastewater using an anaerobic sequencing batch reactor. Desalination 177, 157-165.

Angelidaki, I., Ahring, B.K., Deng, H., Schmidt, J.E., 2002. Anaerobic digestion of olive mill effluents together with swine manure in UASB reactors. Water Science and Technology 45 (10), 213-218.

APHA, AWWA, WPCF, 1998. Standard Methods for the Examination of Water and Wastewater, 20th ed. American Public Health Association, Washington D.C.

Azabou, S., Najjar, W., Bouaziz, M., Ghorbel, A., Sayadi, S., 2010. A compact process for the treatment of olive mill wastewater by combining wet hydrogen peroxide catalytic oxidation and biological techniques. Journal of Hazardous Materials 183 (1-3), 62-69.

Beccari, M., Carucci, G., Majone, M., Torrisi, L., 1999. Role of lipids and phenolic compounds in the anaerobic treatment of olive oil mill effluents. Environmental Technology 20 (1), 105-110.

Boari, G., Brunetti, A., Passino, R., Rozzi, A., 1984. Anaerobic digestion of olive oil mill wastewaters. Agricultural Wastes 10, 161-175.

Cavaleiro, A.J., Salvador, A.F., Alves, J.I., Alves, M.M., 2009. Continuous high rate anaerobic treatment of oleic acid based wastewater is possible after a step feeding start-up. Environmental Science \& Technology 43 (8), 2931-2936.

Cirne, D.G., Paloumet, X., Björnsson, L., Alves, M.M., Mattiasson, B., 2007. Anaerobic digestion of lipid-rich waste - effects of lipid concentration. Renewable Energy 32, 965-975.
Dareioti, M., Dokianakis, S.N., Stamatelatou, K., Zafiri, C., Kornaros, M., 2010. Exploitation of olive mil wastewater and liquid cow manure for biogas production. Waste Management 30 (10), 1841-1848.

Droste, R.L., 1997. Theory and Practice of Water and Wastewater Treatment. John Wiley and Sons, Canada.

Field, J.A., Lettinga, G., 1987. The methanogenic toxicity and anaerobic degradability of a hydrolysable tannin. Water Research 21 (3), 367-374.

Fountoulakis, M., Drakopoulou, S., Terzakis, S., Georgaki, E., Manios, T., 2008. Potential for methane production from typical Mediterranean agro-industrial by-products. Biomass and Bioenergy 32, 155-161.

Gonçalves, M.R., Costa, J.C., Marques, I.P., Alves, M.M., 2011. Inoculum acclimation to oleate promotes the conversion of olive mill wastewater to methane. Energy 36 (4), 2138-2141.

Hamdi, M., 1992. Toxicity and biodegradability of olive mill wastewaters in batch anaerobic digestion. Applied Biochemistry and Biotechnology 37, 155-163.

Hussain, A., Kumar, P., Mehrotra, I., 2008. Treatment of phenolic wastewater in UASB reactor: effect of nitrogen and phosphorous. Bioresource Technology 99, 8497-8503.

Hwu, C.-S., Lier, J.B., Letinga, G., 1998. Physicochemical and biological performance of expanded granular sludge bed reactors treating long-chain fatty acids. Process Biochemistry 33 (1), 75-81.

Jeganathan, J., Nakhla, G., Bassi, A., 2006. Long-term performance of high-rate anaerobic reactors for the treatment of oily wastewater. Environmental Science \& Technology 40, 6466-6472.

Kim, S.-H., Han, S.-K., Shin, H.-S., 2004. Kinetics of LCFA inhibition on acetoclastic methanogenesis, propionate degradation and $\beta$-oxidation. Journal of Environmental Science Health, Part A 39 (4), 1025-1037.

Khouf, S., Aloui, F., Sayadi, S., 2006. Treatment of olive oil mill wastewater by combined process electro-Fenton reaction and anaerobic digestion. Water Research 40, 2007-2016.

Khoufi, S., Aloui, F., Sayadi, S., 2009. Pilot scale hybrid process for olive mill wastewater treatment and reuse. Chemical Engineering and Processing 48, 643-650.

Kuang, Y., Pullammanappallil, P., Lepesteur, M., Ho, G., 2006. Recovery of oleate-inhibited anaerobic digestion by addition of simple substrates. Journal of Chemical Technology and Biotechnology 81, 1057-1063.

Lalman, J., Bagley, D., 2001. Anaerobic degradation and methanogenic inhibitory effects of oleic and stearic acids. Water Research 35 (12), 2975-2983.

Martín-González, L., Castro, R., Pereira, M.A., Alves, M.M., Font, X., Vicent, T., 2011. Thermophilic co-digestion of organic fraction of municipal solid wastes with FOG wastes from a sewage treatment plant: reactor performance and microbial community monitoring. Bioresource Technology 102, 4734-4741.

Morillo, J.A., Antizar-Ladislao, B., Monteoliva-Sánchez, M., Ramos-Cormenzana, A., Russell, N.J., 2009. Bioremediation and biovalorisation of olive-mill wastes. Applied Microbiology and Biotechnology 82 (1), 25-39.

Neves, L., Pereira, M.A., Mota, M., Alves, M.M., 2009a. Detection and quantification of long chain fatty acids in liquid and solid samples and its relevance to understand anaerobic digestion of lipids. Bioresource Technology 100, 91-96.

Neves, L., Oliveira, R., Alves, M.M., 2009b. Fate of LCFA in codigestion of cow manure, food waste and discontinuous addition of oil. Water Research 43, 5142-5150.

Palatsi, J., Illa, J., Prenafeta-Boldú, F.X., Laureni, M., Fernandez, B., Angelidaki, I., Flotats, X., 2010. Long-chain fatty acids inhibition and adaptation process in anaerobic thermophilic digestion: batch tests, microbial community structure and 
mathematical modelling. Bioresource Technology 101, 2243-2251.

Palatsi, J., Laureni, M., Andrés, M.V., Flotats, X., Nielsen, H.B., Angelidaki, I., 2009. Strategies for recovering inhibition caused by long chain fatty acids on anaerobic thermophilic biogas reactors. Bioresource Technology 100 (20), 4588-4596.

Pereira, M.A., Pires, O.C., Mota, M., Alves, M.M., 2002. Anaerobic degradation of oleic acid by suspended and granular sludge: identification of palmitic acid as a key intermediate. Water Science and Technology 45 (10), 139-144.

Pereira, M.A., Pires, O.C., Mota, M., Alves, M.M., 2005. Anaerobic Biodegradation of oleic and palmitic acids: evidence of mass transfer limitations caused by long chain fatty acid accumulation onto the anaerobic sludge. Biotechnology and Bioengineering 92 (1), 15-23.

Pereira, M.A., Sousa, D.Z., Mota, M., Alves, M.M., 2004. Mineralization of LCFA associated to anaerobic sludge: kinetics, transport limitations, enhancement of methanogenic activity and effect of VFA. Biotechnology and Bioengineering 88 (4), 502-511.
Singleton, V.L., Rossi Jr., J.A., 1965. Colorimetry of total phenolics with phosphomolybdic-phosphotungstic acid reagents. American Journal of Enology and Viticulture 16, 144-158.

Sousa, D.Z., 2006. Ecology and physiology of anaerobic microbial communities that degrade long chain fatty acids. $\mathrm{PhD}$ thesis, Dept Biological Eng., University of Minho, Braga, Portugal.

Tripoli, E., Giammanco, M., Tabacchi, G., Majo, D., Giammanco, S., La Guardia, M., 2005. The phenolic compounds of olive oil: structure, biological activity and beneficial effects on human health. Nutrient Research Reviews 18, 98-112.

Zhang, L., Lee, C.-H., Jahng, D., 2011. Restriction of linoleic acid inhibition of methanization of piggery wastewater and enhancement of its mineralization by adding calcium ions. Journal of Chemical Technology and Biotechnology 86, 282-289.

Zouari, N., Ellouz, R., 1996. Toxic effect of coloured olive compounds on the anaerobic digestion of olive oil mill effluent in UASB-like reactors. Journal of Chemical Technology and Biotechnology 66, 414-420. 